\title{
Discharge heart rate and future events among Japanese patients with acute heart failure receiving beta-blocker therapy
}

\author{
Kazuki Oshima $^{1}$, Shun Kohsaka ${ }^{2}$, Kimi Koide ${ }^{2}$, Yuji Nagatomo ${ }^{1}$, Toshiyuki Nagai ${ }^{3}$, Yutaka Endo ${ }^{4}$, \\ Tsutomu Yoshikawa ${ }^{5}$, Keiichi Fukuda ${ }^{2}$ \\ ${ }^{1}$ Department of Cardiology, Saitama City Hospital, Saitama, Japan \\ ${ }^{2}$ Division of Cardiology, Keio University School of Medicine, Tokyo, Japan \\ ${ }^{3}$ National Cerebral and Cardiovascular Center, Osaka, Japan \\ ${ }^{4}$ Japan Red Cross Ashikaga Hospital, Tochigi, Japan \\ ${ }^{5}$ Department of Cardiology, Sakakibara Heart Institute, Tokyo, Japan \\ Email:kohsaka@cpnet.med.keio.ac.jp
}

Received 14 January 2013; revised 24 February 2013; accepted 20 March 2013

\begin{abstract}
Background: Randomized trials have demonstrated the efficacy of beta-blockers (BBs) in heart failure (HF) patients. We sought to assess the impact of $B B s$ on long-term outcome; in particular, we assessed the association between outcome and BB dose and discharge heart rate. Methods and Results: Prescriptions for dispensed medication and outcomes were identified from a prospective, single-institution $\mathrm{HF}$ registry. Long-term prognosis was compared between users and non-users of BBs. BB users were further divided into 2 groups based on dose (full and non-full dose) and discharge heart rate $(<70 \mathrm{bpm}$ and $\geq 70$ bpm). The primary endpoint was defined as either death or hospitalization due to HF. Of 199 patients, 158 (79.4\%) were receiving $\mathrm{BBs}$ at discharge. Their mean age was $66.8 \pm 15.84$ years. Compared with non-users of BBs, BB users were younger (65.0 \pm 15.5 vs $73.8 \pm 13.3$ years, $P=\mathbf{0 . 0 0 1})$ and had a lower ejection fraction $(36.0 \% \pm 14.0 \%$ vs $48.3 \% \pm 11.7 \%, p<$ 0.001). The use of BBs had no effect on long-term outcome $(H R=2.564, P=0.246)$, whereas the eventfree rate was significantly decreased with increasing heart rate (stratified by $70 \mathrm{bpm}$; $\log -\operatorname{rank} P=0.05$ ). A discharge heart rate of $>\mathbf{7 0} \mathbf{b p m}$ was significantly associated with impaired long-term outcome (HR = 1.872, $P=0.04)$. Conclusions: Optimizing heart rate, rather than maximizing $\mathrm{BB}$ dose, appears to be an appropriate treatment strategy for the beta-sensitive Japanese population.
\end{abstract}

Keywords: Heart Failure; Beta-Blocker; Heart Rate; Pharmaceutical Preparations

\section{INTRODUCTION}

Evidence from clinical trials supports the use of pharmacological therapies in heart failure (HF) patients in order to improve their long-term outcome [1]. In addition to angiotensin-converting enzyme inhibitors (ACEi), aldosterone receptor antagonists, and angiotensin II receptor blockers, randomized trials have demonstrated the favorable effect of selective adrenergic receptor antagonists (beta-blockers [BBs]) such as bisoprolol [2-5], sustained-release metoprolol [6,7], and carvedilol [8-13] in $\mathrm{HF}$ with reduced left ventricular systolic function. As a consequence, BBs are recommended for all patients with stable HF and reduced left ventricular ejection fraction (EF) unless contraindicated [1]. Furthermore, although resting heart rate is a prognostic factor in patients with HF $[14,15]$, the optimal heart rate in patients with HF who are receiving $\mathrm{BBs}$ remains unclear. Clinicians therefore attempt to titrate the dose of $\mathrm{BB}$ to the maximum recommended dose, and heart rate is not a focus in routine clinical settings.

In addition, ethnical variability in the use of and response to pharmacological therapies has been reported. It remains unclear how the therapeutic guidelines for $\mathrm{HF}$, which are based on trials mainly conducted on Caucasian populations, can be implemented for ethnically different populations, particularly, Asian HF patients. Research on the patterns and practice outcomes in non-western countries is important since the majority of landmark studies are conducted in western countries. Furthermore, there are significant racial differences in response to $\mathrm{BBs}$, and limited studies have been performed on Asian populations [16]. A study conducted in China showed large interethnic differences in the sensitivity and frequencies of genotype polymorphisms of the renin-angiotensin system 
[17]. In a clinical setting, Seow et al. reported high mortality in multiethnic Southeast Asian patients $(67 \%$ in 5 years) despite high use of ACEi (79\%), albeit with low use of BBs (5\%) [18].

We sought to investigate the impact of the use of BBs on long-term outcome in patients who were admitted to a tertiary hospital for treatment of decompensated HF. In addition, we analyzed the effects of BB dose and discharge heart rate.

\section{METHODS}

\subsection{Study Design and Patient Population}

HF patients who were admitted to Keio University Hospital for HF exacerbation and successfully discharged during the period from January 2006 to August 2010 were consecutively recruited. Patients with a pacemaker $(\mathrm{n}=25)$ were excluded, as were patients with no information on discharge heart rate $(\mathrm{n}=7)$ or BB dose $(\mathrm{n}=$ $30)$, those who did not have follow-up data $(\mathrm{n}=37)$, and those for whom the date of discharge was unknown $(\mathrm{n}=$ 6). From 298 recruits, the final study population comprised 199 patients. The study protocol conformed to the ethical guidelines of the 1975 Declaration of Helsinki, and the study was approved by the institution's human research committee.

Patients were divided into 2 groups based on the use or non-use of BBs. BB users were stratified on the basis of the dose of these medications (full dose or non-full dose). Of note, the maximum dose of BBs recommended by the Ministry of Health, Labor and Welfare in Japan is about half the dose recommended by western countries, for example, recommended dose for carvedilol $10 \mathrm{mg}$ twice daily and bisoprolol $5 \mathrm{mg}$ daily in Japan.

Furthermore, we divided BB users into 2 groups based on a discharge heart rate close to the average discharge heart rate of $72.6 \mathrm{bpm}$ : those with a heart rate of $<70$ $\mathrm{bpm}$ and those with a heart rate of $\geq 70 \mathrm{bpm}$. Heart rate was measured at rest by a registered nurse before breakfast on the day of discharge. Average length of stay was 19.0 days in our cohort, which was an appropriate interval to achieve BB equilibrium.

\subsection{Biomarker Measurement}

CKD was defined as estimated GFR (eGFR) of $<60$ $\mathrm{mL} / \mathrm{min}$. Diabetes mellitus was defined according to the criteria of the American Diabetes Association. Clinical data were obtained from hospital medical charts. Plasma brain natriuretic peptide (BNP) level and other biomarkers were also measured before discharge. Commercially available assay kits were used for the measurement of BNP (Shionogi, Tokyo, Japan), cardiac troponin T (cTnT; Roche Diagnostics, Tokyo, Japan), and high-sensitivity C-reactive protein (hsCRP; Dade Behring Marburg,
Tokyo, Japan). The lower limit of detection of cTnT was $0.01 \mathrm{ng} / \mathrm{mL}$. Serum creatinine and hemoglobin levels were determined by standard laboratory methods. GFR was estimated using the equation from the Modification of Diet in Renal Disease Study: eGFR

$\left(\mathrm{mL} \cdot \mathrm{min}^{-1} \cdot 1.73 \cdot \mathrm{m}^{-2}\right)=0.741 \times 175 \times \mathrm{Age}^{-0.203} \times$ $\mathrm{SCr}^{-1.154}(\times 0.724$ for females $)$ [19].

\subsection{Follow-Up}

The primary endpoint was all-cause mortality and HF requiring hospitalization. Follow-up information was obtained from medical records and inquiries directed at patients or their families via mail or telephone. Information was available for all $(100 \%)$ patients. The patients were predominantly followed by cardiologists in a tertiary care setting.

\subsection{Statistical Analysis}

Categorical variables were expressed as numbers (percentages), and continuous variables were expressed as the mean \pm standard deviation. An unpaired t-test and chi-square test were used for between-group comparison of continuous and categorical variables, respectively. Overall survival and survival without hospitalization for HF were analyzed by the Kaplan-Meier method, and the curves were compared by the log-rank test. Multivariate Cox regression analyses were performed to assess the impact of medication on outcome. The multivariate model included categorical variables that were statistically significant according to a univariate analysis as well as clinically important. A P-value of $<0.05$ was considered significant. Statistical analyses were performed with PASW Statistics 18.

\section{RESULTS}

\subsection{Baseline Characteristics}

A total of 199 patients were analyzed for this study, and $158(79.4 \%)$ were on BBs at discharge. Most patients were on carvedilol $(\mathrm{n}=152)$, and a few were on bisoprolol or atenolol ( $\mathrm{n}=3$ respectively). The mean age was 66.8 years; $70.3 \%$ of patients were men. The prevalence of ischemic cardiomyopathy, diabetes mellitus, and CKD was $30.2 \%, 32.2 \%$, and $66.8 \%$, respectively. A total of $158(79.4 \%)$ patients were receiving renin-angiotensin system inhibitors (RASi).

The mean hemoglobin level was $13.0 \mathrm{~g} / \mathrm{dl}$. The median follow-up period for this cohort was 1.5 years (interquartile range, $0.6-2.6$ years).

Compared to non-users of BBs, BB users were younger $(65.0 \pm 15.5$ vs $73.8 \pm 13.3$ years, $\mathrm{P}=0.001)$ and had a lower EF $(36.0 \% \pm 14.0 \%$ vs $48.3 \% \pm 11.7 \%, \mathrm{P}<0.001)$. The prevalence of ischemic cardiomyopathy was also 
higher among BB users $(34.2 \%$ vs $14.6 \%, \mathrm{P}=0.015)$ (Table 1). The primary endpoint was observed in 58 (36.7\%) BB users and in 13 (31.7\%) BB non-users (logrank test $\mathrm{P}=0.860$ ) (Figure 1). Cox proportional hazard analysis revealed that $\mathrm{BB}$ use had no influence on long-term outcome after adjustment for baseline $\mathrm{EF}$ and age, CKD, creatinine, BNP, RASi use, and potassium, which were identified as significant in the univariate analysis $(\mathrm{HR}=2.564, \mathrm{P}=0.246)$.

\subsection{Dose of Beta-Blockers}

Of the 158 BB users, 19 and 139 were receiving a full dose and a non-full dose, respectively. The BNP value was lower among patients who were receiving the full dose of BB $(220.6 \pm 148.9$ vs $368.4 \pm 445.0, \mathrm{P}=0.007)$ (Table 2). The primary endpoint was observed in 8 (42.1\%) patients receiving the full dose and in $50(36.0 \%)$ patients receiving a non-full dose of a $\mathrm{BB}$ (log-rank test,

Table 1. Baseline characteristics by use of BB.

\begin{tabular}{|c|c|c|c|c|}
\hline Variables & $\begin{array}{c}\text { All } \\
\mathrm{n}=199\end{array}$ & $\begin{array}{c}\text { on BB } \\
\mathrm{n}=158\end{array}$ & $\begin{array}{c}\text { not on BB } \\
n=41\end{array}$ & P-value \\
\hline \multicolumn{5}{|c|}{ Demographics } \\
\hline Age, (yrs) & $66.8 \pm 15.4$ & $65.0 \pm 15.5$ & $73.8 \pm 13.3$ & 0.001 \\
\hline Male, $(\%)$ & $140(70.3)$ & $116(73.4)$ & $24(58.5)$ & 0.063 \\
\hline Jugular venous distention, $(\%)$ & $92(46.2)$ & $68(43.0)$ & $24(58.5)$ & 0.172 \\
\hline Third heart sound, $(\%)$ & $112(56.3)$ & $87(55.1)$ & $25(61.0)$ & 0.522 \\
\hline Coarse crackle, $(\%)$ & $64(32.2)$ & $46(29.1)$ & $18(43.9)$ & 0.219 \\
\hline Orthopnea, $(\%)$ & $51(25.6)$ & $37(23.4)$ & $13(31.7)$ & 0.412 \\
\hline Ischemic cardiomyopathy, $(\%)$ & $60(30.2)$ & $54(34.2)$ & $6(14.6)$ & 0.015 \\
\hline Ejection fraction, $(\%)$ & $37.5 \pm 13.6$ & $36.0 \pm 14.0$ & $48.3 \pm 11.7$ & $<0.001$ \\
\hline NYHA Class III to IV on Admission, (\%) & $146(73.4)$ & $113(73.4)$ & $33(82.5)$ & 0.234 \\
\hline Diabetes mellitus, $(\%)$ & $64(32.2)$ & $53(33.5)$ & $11(26.8)$ & 0.412 \\
\hline Hypertension, $(\%)$ & $82(41.2)$ & $65(41.1)$ & $17(41.5)$ & 0.532 \\
\hline Dyslipidemia, (\%) & $58(29.1)$ & $47(29.7)$ & $11(26.8)$ & 0.654 \\
\hline Chronic kidney Disease, $(\%)$ & $133(66.8)$ & $104(66.2)$ & $29(70.7)$ & 0.586 \\
\hline Atrial fibrillation and/or atrial flutter, $(\%)$ & $59(29.6)$ & $37(23.4)$ & $22(53.7)$ & $<0.001$ \\
\hline Smoking, (\%) & $53(26.6)$ & $45(40.5)$ & $8(32.0)$ & 0.429 \\
\hline Heart rate at discharge, $(\mathrm{bpm})$ & $72.6 \pm 14.9$ & $74.2 \pm 14.1$ & $66.4 \pm 16.1$ & 0.002 \\
\hline Systolic blood pressure on admission, $(\mathrm{mmHg})$ & $131.4 \pm 29.3$ & $130.7 \pm 29.9$ & $134.0 \pm 27.3$ & 0.522 \\
\hline Systolic blood pressure at discharge, $(\mathrm{mmHg})$ & $110.2 \pm 18.6$ & $108.6 \pm 18.6$ & $116.4 \pm 17.2$ & 0.016 \\
\hline Creatinine $(\mathrm{mg} / \mathrm{dl})$ on admission & $1.16 \pm 0.79$ & $1.2 \pm 0.9$ & $1.1 \pm 0.4$ & 0.850 \\
\hline $\mathrm{Hb}$ on admission, $(\mathrm{g} / \mathrm{dl})$ & $13.0 \pm 2.4$ & $13.1 \pm 2.3$ & $12.5 \pm 2.4$ & 0.127 \\
\hline Sodium (mmol/l) on admission & $139.5 \pm 3.7$ & $139.5 \pm 3.9$ & $139.5 \pm 3.2$ & 0.962 \\
\hline \multicolumn{5}{|c|}{ Discharge medications } \\
\hline RASi, $(\%)$ & $158(79.4)$ & $128(81.0)$ & $30(73.2)$ & 0.269 \\
\hline Loop diuretics, $(\%)$ & $126(63.3)$ & $97(61.8)$ & $29(70.7)$ & 0.289 \\
\hline Furosemide dose, $(\mathrm{mg})$ & $22.6 \pm 28.5$ & $23.4 \pm 30.9$ & $19.2 \pm 15.2$ & 0.233 \\
\hline Spironolactone, $(\%)$ & $105(52.8)$ & $88(56.1)$ & $17(41.5)$ & 0.096 \\
\hline \multicolumn{5}{|c|}{ Biomarkers } \\
\hline $\mathrm{BNP},(\mathrm{pg} / \mathrm{ml})$ & $331.1 \pm 399.3$ & $351.7 \pm 424.5$ & $251.6 \pm 271.0$ & 0.162 \\
\hline Troponin $\mathrm{T},(\mathrm{ng} / \mathrm{ml})$ & $0.02 \pm 0.09$ & $0.02 \pm 0.10$ & $0.01 \pm 0.02$ & 0.699 \\
\hline high-sensitive CRP, $(\mathrm{ng} / \mathrm{ml})$ & $4830.5 \pm 8575.1$ & $4301.5 \pm 7642.1$ & $6892.0 \pm 11406.6$ & 0.092 \\
\hline oxidized LDL, (U/1) & $104.5 \pm 37.7$ & $108.6 \pm 37.8$ & $88.9 \pm 33.5$ & 0.003 \\
\hline
\end{tabular}

Values are expressed as mean $\pm \mathrm{SD}$ or $\mathrm{n}(\%)$. P refers to comparison between patients who were on BB and those who were not on BB. BB, beta blocker; $\mathrm{BNP}$, brain natriuretic peptide; CRP, C-reactive protein; Hb, hemoglobin; NYHA, New York Heart Association; RASi, renin-angiotensin system inhibitor. 
Table 2. Baseline characteristics by dose of BB.

\begin{tabular}{|c|c|c|c|}
\hline Variables & $\begin{array}{l}\text { Full dose Group } \\
n=19\end{array}$ & $\begin{array}{l}\text { Non-Full dose Group } \\
\mathrm{n}=139\end{array}$ & P-value \\
\hline \multicolumn{4}{|c|}{ Demographics } \\
\hline Age, (yrs) & $64.5 \pm 12.8$ & $65.1 \pm 15.8$ & 0.876 \\
\hline Male, $(\%)$ & $15(78.9)$ & $101(72.7)$ & 0.561 \\
\hline Jugular venous distention, (\%) & $8(42.1)$ & $60(43.2)$ & 0.589 \\
\hline Third heart sound, (\%) & $13(68.4)$ & $74(53.2)$ & 0.160 \\
\hline Coarse crackle, $(\%)$ & $8(42.1)$ & $38(27.3)$ & 0.145 \\
\hline Orthopnea, $(\%)$ & $4(21.1)$ & $33(23.7)$ & 0.775 \\
\hline Ischemic cardiomyopathy, $(\%)$ & $9(47.4)$ & $45(32.4)$ & 0.196 \\
\hline Ejection fraction (\%) & $35.0 \pm 15.8$ & $36.1 \pm 13.8$ & 0.993 \\
\hline NYHA Class III to IV on Admission, (\%) & $16(88.9)$ & $97(71.3)$ & 0.113 \\
\hline Diabetes mellitus, $(\%)$ & $6(31.6)$ & $47(33.8)$ & 0.847 \\
\hline Hypertension, (\%) & $10(52.6)$ & $55(39.6)$ & 0.278 \\
\hline Dyslipidemia, (\%) & $9(47.4)$ & $38(27.3)$ & 0.073 \\
\hline Chronic kidney disease, $(\%)$ & $13(68.4)$ & $91(65.9)$ & 0.830 \\
\hline Atrial fibrillation and/or atrial flutter, $(\%)$ & $4(21.1)$ & $33(23.7)$ & 0.795 \\
\hline Smoking, (\%) & $5(35.7)$ & $40(41.2)$ & 0.694 \\
\hline Heart rate at discharge, $(\mathrm{bpm})$ & $68.5 \pm 13.9$ & $75.0 \pm 14.1$ & 0.062 \\
\hline Systolic blood pressure on admission, $(\mathrm{mmHg})$ & $128.4 \pm 34.9$ & $131.0 \pm 29.3$ & 0.728 \\
\hline Systolic blood pressure at discharge, $(\mathrm{mmHg})$ & $110.0 \pm 17.3$ & $108.4 \pm 18.9$ & 0.728 \\
\hline Creatinine $(\mathrm{mg} / \mathrm{dl})$ on admission & $1.1 \pm 0.4$ & $1.2 \pm 0.9$ & 0.746 \\
\hline $\mathrm{Hb}$ on admission, $(\mathrm{g} / \mathrm{dl})$ & $12.7 \pm 1.9$ & $13.1 \pm 2.4$ & 0.439 \\
\hline Sodium $(\mathrm{mmol} / \mathrm{l})$ on admission & $140.1 \pm 3.6$ & $139.4 \pm 3.9$ & 0.511 \\
\hline \multicolumn{4}{|c|}{ Discharge medications } \\
\hline RASi, (\%) & $17(89.5)$ & $111(79.9)$ & 0.316 \\
\hline Loop diuretics, $(\%)$ & $13(68.4)$ & $84(60.9)$ & 0.525 \\
\hline Furosemide dose, (mg) & $31.6 \pm 41.8$ & $22.3 \pm 29.0$ & 0.219 \\
\hline Spironolactone, $(\%)$ & $11(57.9)$ & $77(55.8)$ & 0.863 \\
\hline \multicolumn{4}{|c|}{ Biomarkers } \\
\hline $\mathrm{BNP},(\mathrm{pg} / \mathrm{ml})$ & $220.6 \pm 148.9$ & $368.4 \pm 445.0$ & 0.007 \\
\hline Troponin T, (ng/ml) & $0.00 \pm 0.01$ & $0.02 \pm 0.11$ & 0.444 \\
\hline high-sensitive CRP, (ng/ml) & $4301.8 \pm 6787.0$ & $4301.5 \pm 7766.0$ & 0.999 \\
\hline oxidized LDL, (U/1) & $104.1 \pm 38.4$ & $109.1 \pm 37.8$ & 0.610 \\
\hline
\end{tabular}

Values are expressed as mean $\pm \mathrm{SD}$ or $\mathrm{n}(\%)$. BB, beta blocker; BNP, brain natriuretic peptide; CRP, C-reactive protein; Hb, hemoglobin; NYHA, New York Heart Association; RASi, renin-angiotensin system inhibitor.

$\mathrm{P}=0.701$ ) (Figure 2). Cox proportional hazard analysis revealed that the BB dose had no influence on long-term outcome after adjustment for age, gender, and baseline EF (HR 1.173, P = 0.680).

\subsection{Beta-Blockers and Heart Rate}

Of the $158 \mathrm{BB}$ users, 61 had a discharge heart rate of $<70$ $\mathrm{bpm}$. There were no significant differences between the 2 groups in terms of age $(\mathrm{P}=0.770)$, prevalence of diabetes mellitus $(\mathrm{P}=0.392), \mathrm{CKD}(\mathrm{P}=0.837)$, use of RASi such as ACEi $(\mathrm{P}=0.282)$, and BNP $(\mathrm{P}=0.300)$ (Table 3). The primary endpoint was observed in $16(26.2 \%)$ and $42(43.4 \%)$ patients with a discharge heart rate of $<70$ bpm and $\geq 70$ bpm, respectively (log-rank $\mathrm{P}=0.05$ ) (Figure 3). Discharge heart rate was a significant predictor of long-term outcome after adjustment for age, gender, and baseline EF (HR 1.872; P = 0.040). Furthermore, discharge heart rate was not correlated with BB dose at discharge among BB users (Spearman Rank Correlation Coefficient $=-0.012, \mathrm{P}=0.858$ ). 


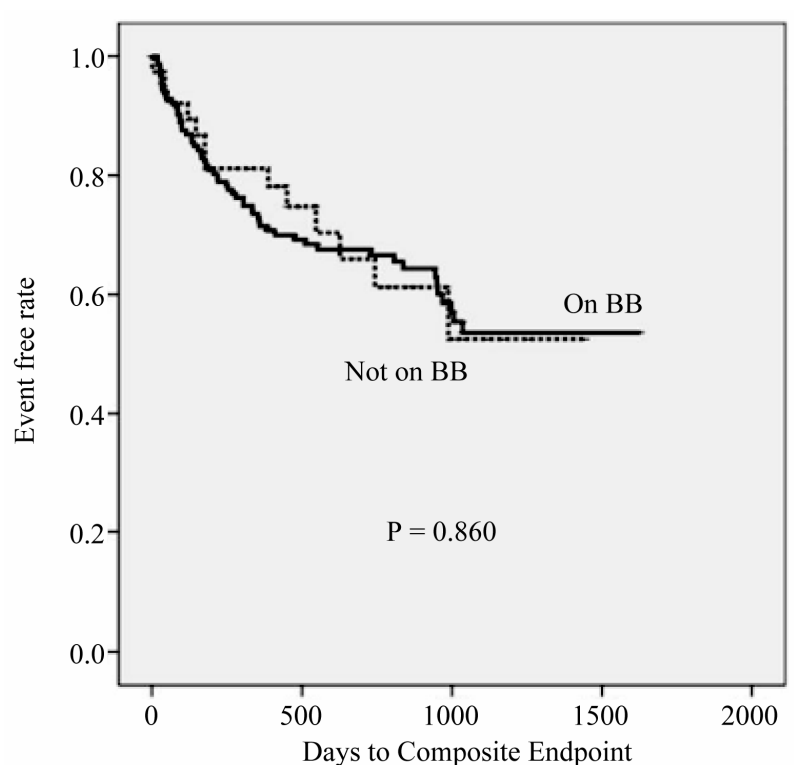

Figure 1. Kaplan-Meier event curve for on vs not on BB group.

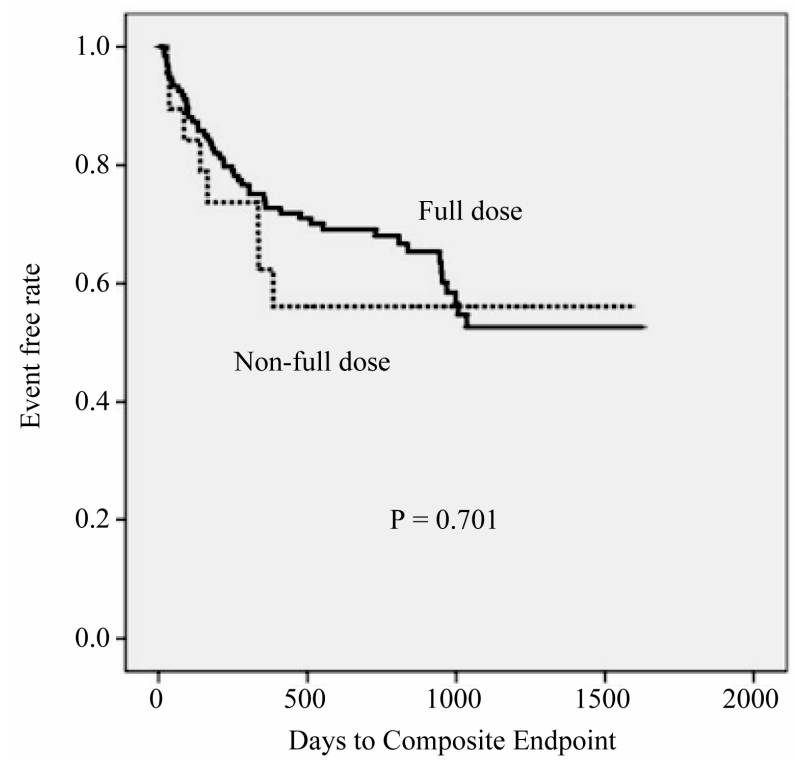

Figure 2. Kaplan-Meier event curve for full dose vs not-full dose group.

\section{DISCUSSION}

The main findings of the present study were as follows: 1) BB prescriptions based on physician preference had a limited impact on outcome in a cohort of Japanese HF patients who had recovered from recent acute decompensation; 2) full dose of BBs was not associated with improved outcome; 3) optimal heart rate appeared to reduce the risk of a $\mathrm{HF}$ event in $\mathrm{BB}$ users.

European and American guidelines for the treatment of HF have reached a consensus by incorporating numerous published studies and knowledge into clinical practice. $[20,21]$ The use of RASi, diuretics, and BBs in the ma-

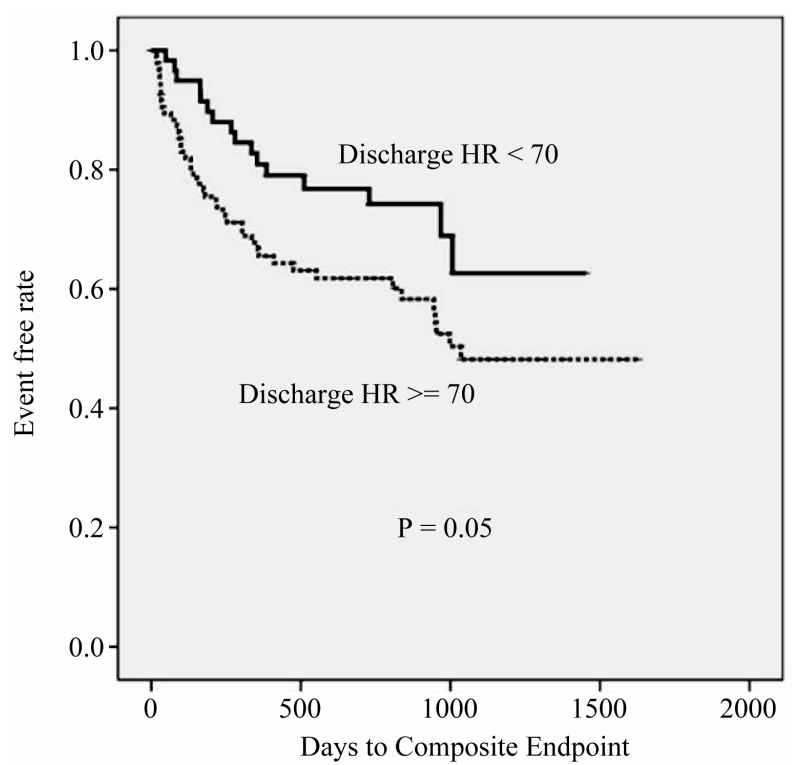

Figure 3. Kaplan-Meier event curve for $\mathrm{HR}>70$ vs $\mathrm{HR} \leq 70$ group.

jority of HF patients was already recommended at the time of our study [20,21]. Overall, adherence to evidence-based medication in the present study was consistent with that in western countries; $79.4 \%$ of the patients received RASi at discharge, which is comparable to the approximately $60 \%$ in Europe $[22,23]$ and $88 \%$ in the United States [24]. Similarly, $79.4 \%$ of our patients were discharged with a $\mathrm{BB}$; this percentage was $83.5 \%$ in the US [25]. Traditionally, the number of clinical research studies performed in Japan has been limited, and prescription of guideline-based medication has been low compared to that in western countries. For example, in a multicenter, prospective cohort study conducted in Japan between 2000 and 2005, only $29.9 \%$ of patients with chronic HF were using a BB [26]. In another Japanese registry study performed between 2004 and 2005, 65.9\% of patients with systolic dysfunction were using a BB at the time of hospital discharge. The majority of patients taking a BB received carvedilol (89.8\%) [27]. Although our study was limited to a single academic institution, we believe that improvement of the BB prescription rate and RASi use represents strong implementation of evidencebased therapy in Japan.

Resting heart rate is a prognostic factor in patients with $\mathrm{HF}[14,15]$, but the optimal heart rate in patients with HF who are using BBs remains unclear. Therefore, clinicians attempt to titrate the dose of $\mathrm{BB}$ to the maximum recommended dose, and heart rate is not a focus in routine clinical settings. In the present study, a discharge heart rate of $<70 \mathrm{bpm}$ was associated with improved outcome in BB users. In the SHIFT study, a direct association was found between baseline heart rate and 
Table 3. Baseline characteristics of patients discharged on beta-blocker, stratified by discharge heart rate.

\begin{tabular}{|c|c|c|c|}
\hline Variables & $\begin{array}{c}\mathrm{HR}<70 \text { Group } \\
\mathrm{n}=61\end{array}$ & $\begin{array}{c}\mathrm{HR} \geq 70 \text { Group } \\
\mathrm{n}=97\end{array}$ & P-value \\
\hline \multicolumn{4}{|c|}{ Demographics } \\
\hline Age, (yrs) & $65.4 \pm 13.3$ & $64.7 \pm 16.8$ & 0.770 \\
\hline Male, $(\%)$ & $43(70.5)$ & $73(75.3)$ & 0.580 \\
\hline Jugular venous distention, (\%) & $31(59.8)$ & $37(38.1)$ & 0.182 \\
\hline Third heart sound, $(\%)$ & $40(65.6)$ & $47(48.5)$ & 0.037 \\
\hline Coarse crackle, $(\%)$ & $20(32.8)$ & $26(26.8)$ & 0.606 \\
\hline Orthopnea, $(\%)$ & $18(29.5)$ & $19(19.6)$ & 0.108 \\
\hline Ischemic cardiomyopathy, (\%) & $25(41.0)$ & $29(29.9)$ & 0.171 \\
\hline Ejection fraction $(\%)$ & $35.1 \pm 13.9$ & $37.6 \pm 14.1$ & 0.738 \\
\hline NYHA Class III to IV on Admission, (\%) & $49(80.3)$ & $64(68.8)$ & 0.137 \\
\hline Diabetes mellitus, $(\%)$ & $23(37.7)$ & $30(30.9)$ & 0.392 \\
\hline Hypertension, $(\%)$ & $25(41.0)$ & $40(41.2)$ & 0.975 \\
\hline Dyslipidemia, $(\%)$ & $18(29.5)$ & $29(29.9)$ & 0.959 \\
\hline Chronic kidney disease, $(\%)$ & $41(67.2)$ & $63(64.9)$ & 0.837 \\
\hline Atrial fibrillation and/or atrial flutter, $(\%)$ & $22(25.6)$ & $37(32.7)$ & 0.273 \\
\hline Smoking, $(\%)$ & $18(29.5)$ & $27(27.8)$ & 0.375 \\
\hline Heart rate at discharge, $(\mathrm{bpm})$ & $60.5 \pm 6.1$ & $82.8 \pm 10.5$ & $<0.001$ \\
\hline Systolic blood pressure on admission, $(\mathrm{mmHg})$ & $127.0 \pm 32.7$ & $133.0 \pm 27.9$ & 0.217 \\
\hline Systolic blood pressure at discharge, $(\mathrm{mmHg})$ & $106.9 \pm 16.6$ & $109.7 \pm 19.8$ & 0.369 \\
\hline Creatinine $(\mathrm{mg} / \mathrm{dl})$ on admission & $1.1 \pm 0.3$ & $1.2 \pm 1.1$ & 0.280 \\
\hline $\mathrm{Hb}$ on admission, $(\mathrm{g} / \mathrm{dl})$ & $13.0 \pm 2.2$ & $13.1 \pm 2.4$ & 0.797 \\
\hline Sodium $(\mathrm{mmol} / \mathrm{l})$ on admission & $140.0 \pm 2.8$ & $139.1 \pm 4.3$ & 0.156 \\
\hline \multicolumn{4}{|c|}{ Discharge medications } \\
\hline RASi, $(\%)$ & $52(85.2)$ & $76(78.4)$ & 0.282 \\
\hline Dose of BB (carvedilol equivalent), (mg) & $9.25 \pm 6.22$ & $7.85 \pm 5.09$ & 0.128 \\
\hline Loop diuretics, $(\%)$ & $39(63.9)$ & $58(60.4)$ & 0.737 \\
\hline Furosemide dose, $(\mathrm{mg})$ & $24.0 \pm 30.1$ & $23.0 \pm 31.6$ & 0.842 \\
\hline Spironolactone, $(\%)$ & $29(47.5)$ & $59(61.5)$ & 0.100 \\
\hline \multicolumn{4}{|c|}{ Biomarker levels at discharge } \\
\hline $\mathrm{BNP},(\mathrm{pg} / \mathrm{ml})$ & $306.9 \pm 293.5$ & $380.5 \pm 489.8$ & 0.300 \\
\hline Troponin T, (ng/ml) & $0.02 \pm 0.15$ & $0.02 \pm 0.07$ & 0.584 \\
\hline high-sensitive CRP, (ng/ml) & $4844.3 \pm 10267.5$ & $3947.5 \pm 5313.8$ & 0.481 \\
\hline oxidized LDL, (U/l) & $106.0 \pm 33.5$ & $110.2 \pm 40.4$ & 0.504 \\
\hline
\end{tabular}

Values are expressed as mean $\pm \mathrm{SD}$ or $\mathrm{n}(\%)$. BB, beta blocker; BNP, brain natriuretic peptide; CRP, C-reactive protein; Hb, hemoglobin; NYHA, New York Heart Association; RASi, renin-angiotensin system inhibitor.

outcomes in patients with HF who were in sinus rhythm with a heart rate of $\geq 70 \mathrm{bpm}$ [28]. Moreover, in a metaanalysis of BB trials on HF conducted in western countries, the benefit on mortality was related to the reduction in heart rate achieved in each trial, and was not related to the BB dose [29].

In the present study, patients who were receiving a full dose of a BB did not have an improved outcome com- pared to those who were not receiving a full dose. There is little information on the response to BBs among Japanese patients. In 1 small study, carvedilol reduced hospitalization for cardiovascular disease in a dose-dependent fashion, and even a low dose of carvedilol (as low as 5 $\mathrm{mg}$ /day) was effective [30].

In controlled clinical trials, the $\mathrm{BB}$ dose is not determined by a patient's therapeutic response, but is increased 
until the patient has received a prespecified target dose. Low doses are prescribed only if the target doses are not tolerated; therefore, most trials have not evaluated whether low doses are effective. The implication is that physicians, especially cardiologists and primary care physicians, should make every effort to achieve the target doses of the BB shown to be effective in major clinical trials [1]. Our results challenge the above notion and indicate that optimizing heart rate, rather than maximizing dose, is an appropriate treatment strategy for the betasensitive Japanese population.

Despite aggressive use of BBs in our population, the impact of BBs might have been diluted by the physician's preference for its use. One study reported that more than a quarter of users discontinued BBs in the first year after hospitalization and that the 5-year compliance rate was $53 \%$ [31]. In a study conducted in the US, withdrawal of BBs was associated with a substantially higher adjusted risk of mortality compared with $\mathrm{BB}$ continuation, but with a similar risk to that of eligible HF patients not treated with BBs. Furthermore, users of BBs had a lower EF, which can contribute to higher mortality. Multivariate regression analysis of covariates such as age, CKD, creatinine, BNP, RASi use, and potassium, which were shown to be significant in univariate analysis, revealed no significant differences between the 2 groups (users and non-users of BBs; HR $=2.914, \mathrm{P}=0.16$ ). However, the applicability of these results may be limited by the low number of patients included in our analysis.

There are several limitations to the current study. Although the results remained significant, we were unable to adjust for significant variables in the subgroup analysis since the number of patients included in this study was relatively small. Further, adherence to evidencebased medication may have impacted the outcome. In our cohort, the BB dose remained the same in $53.2 \%$ of the patients during the follow-up period, but due to the limited number of patients and the short follow-up period, we did not perform any additional analyses. We did not classify patients based on systolic and diastolic HF, although not all HF patients have a similar response and outcome from this perspective. Lastly, use of spironolactone in symptomatic HF patients with systolic left ventricular dysfunction was not included in our analysis. Various comorbidities, such as renal insufficiency or hypotension, may have contributed to non-adherence to evidence-based medication. However, without rigid prospective definitions, it is not possible to determine whether other solutions could be found without discontinuing these agents.

In conclusion, BB therapy was not associated with better long-term outcomes in this cohort. Our results suggest that in BB therapy, optimizing heart rate is more impor- tant than dose titration.

\section{ACKNOWLEDGEMENTS}

We wish to acknowledge the patients involved in the cohort.

\section{REFERENCES}

[1] Hunt, S.A., Abraham, W.T., Chin, M.H., Feldman, A.M., Francis, G.S., Ganiats, T.G., Jessup, M., Konstam, M.A., Mancini, D.M., Michl, K., et al. (2009) 2009 focused update incorporated into the ACC/AHA 2005 Guidelines for the diagnosis and management of heart failure in adults: A report of the American College of Cardiology Foundation/American Heart Association Task Force on practice guidelines: Developed in collaboration with the International Society for Heart and Lung Transplantation. Circulation, 119, e391-e479. doi:10.1161/CIRCULATIONAHA.109.192065

[2] (1999) The cardiac insufficiency bisoprolol study II (CIBIS-II): A randomised trial. Lancet, 353, 9-13. doi:10.1016/S0140-6736(98)11181-9

[3] Leizorovicz, A., Lechat, P., Cucherat, M. and Bugnard, F. (2002) Bisoprolol for the treatment of chronic heart failure: A meta-analysis on individual data of two placebocontrolled studies - CIBIS and CIBIS II. Cardiac insufficiency bisoprolol study. American Heart Journal, 143, 301-307. doi:10.1067/mhj.2002.120768

[4] Lechat, P., Escolano, S., Golmard, J.L., Lardoux, H., Witchitz, S., Henneman, J.A., Maisch, B., Hetzel, M., Jaillon, P., Boissel, J.P., et al. (1997) Prognostic value of bisoprolol-induced hemodynamic effects in heart failure during the cardiac insufficiency bisoprolol study (CIBIS). Circulation, 96, 2197-2205. doi:10.1161/01.CIR.96.7.2197

[5] CIBIS Investigators and Committees (1994) A randomized trial of beta-blockade in heart failure. The Cardiac Insufficiency Bisoprolol Study (CIBIS). Circulation, 90, 1765-1773.

[6] Hjalmarson, A., Goldstein, S., Fagerberg, B., Wedel, H., Waagstein, F., Kjekshus, J., Wikstrand, J., El Allaf, D., Vitovec, J., Aldershvile, J., et al. (2000) Effects of controlled-release metoprolol on total mortality, hospitalizations, and well-being in patients with heart failure: The metoprolol $\mathrm{CR} / \mathrm{XL}$ randomized intervention trial in congestive heart failure (MERIT-HF). JAMA, 283, 12951302. doi:10.1001/jama.283.10.1295

[7] Waagstein, F., Bristow, M.R., Swedberg, K., Camerini, F., Fowler, M.B., Silver, M.A., Gilbert, E.M., Johnson, M.R., Goss, F.G. and Hjalmarson, A. (1993) Beneficial effects of meto-prolol in idiopathic dilated cardiomyopathy. Lancet, 342, 1441-1446. doi:10.1016/0140-6736(93)92930-R

[8] Dargie, H.J. (2001) Effect of carvedilol on outcome after myocardial infarction in patients with left-ventricular dysfunction: The CAPRICORN rando-mised trial. Lancet, 357, 1385-1390. doi:10.1016/S0140-6736(00)04560-8

[9] Packer, M., Coats, A.J., Fowler, M.B., Katus, H.A., Krum, H., Mohacsi, P., Rouleau, J.L., Tendera, M., Castaigne, A., Roecker, E.B., et al. (2001) Effect of carvedilol on survival in severe chronic heart failure. The New England 
Journal of Medicine, 344, 1651-1658. doi:10.1056/NEJM200105313442201

[10] Colucci, W.S., Packer, M., Bristow, M.R., Gilbert, E.M., Cohn, J.N., Fowler, M.B., Krueger, S.K., Hershberger, R., Uretsky, B.F., Bowers, J.A., et al. (1996) Carvedilol inhibits clinical progression in patients with mild symptoms of heart failure. Circulation, 94, 2800-2806.

doi:10.1161/01.CIR.94.11.2800

[11] Bristow, M.R., Gilbert, E.M., Abraham, W.T., Adams, K.F., Fowler, M.B., Hershberger, R.E., Kubo, S.H., Narahara, K.A., Ingersoll, H., Krueger, S., et al. (1996) Carvedilol produces dose-related improvements in left ventricular function and survival in subjects with chronic heart failure. Circulation, 94, 2807-2816. doi:10.1161/01.CIR.94.11.2807

[12] Packer, M., Colucci, W.S., Sackner-Bernstein, J.D., Liang, C.S., Goldscher, D.A., Freeman, I., Kukin, M.L., Kinhal, V., Udelson, J.E., Klapholz, M., et al. (1996) Double-blind, placebo-controlled study of the effects of carvedilol in patients with moderate to severe heart failure. The PRE-CISE Trial. Prospective randomized evaluation of carvedilol on symptoms and exercise. Circulation, 94, 2793-2799. doi:10.1161/01.CIR.94.11.2793

[13] Packer, M., Bristow, M.R., Cohn, J.N., Colucci, W.S., Fowler, M.B., Gilbert, E.M. and Shusterman, N.H. (1996) The effect of carvedilol on morbidity and mortality in patients with chronic heart failure. The New England Journal of Medicine, 334, 1349-1355.

doi:10.1056/NEJM199605233342101

[14] Fox, K., Ford, I., Steg, P.G., Tendera, M. and Ferrari, R. (2008) Ivabradine for patients with stable coronary artery disease and left-ventricular systolic dysfunction (BEAUTIFUL): A randomised, double-blind, placebo-controlled trial. Lancet, 372, 807-816. doi:10.1016/S0140-6736(08)61170-8

[15] Fosbol, E.L., Seibaek, M., Brendorp, B., Moller, D.V., Thune, J.J., Gislason, G.H., Torp-Pedersen, C. and Kober, L. (2010) Long-term prognostic importance of resting heart rate in patients with left ventricular dysfunction in connection with either heart failure or myocardial infarction: The DIAMOND study. International Journal of Cardiology, 140, 279-286. doi:10.1016/j.ijcard.2008.11.084

[16] Zhou, H.H., Koshakji, R.P., Silberstein, D.J., Wilkinson, G.R. and Wood, A.J. (1989) Altered sensitivity to and clearance of propranolol in men of Chinese descent as compared with American whites. The New England Journal of Medicine, 320, 565-570.

doi:10.1056/NEJM198903023200905

[17] Sanderson, J.E., Yu, C.M., Young, R.P., Shum, I.O., Wei, S., Arumanayagam, M. and Woo, K.S. (1999) Influence of gene polymorphisms of the renin-angiotensin system on clinical outcome in heart failure among the Chinese. American Heart Journal, 137, 653-657. doi:10.1016/S0002-8703(99)70218-8

[18] Seow, S.C., Chai, P., Lee, Y.P., Chan, Y.H., Kwok, B.W., Yeo, T.C. and Chia, B.L. (2007) Heart failure mortality in Southeast Asian patients with left ventricular systolic dysfunction. Journal of Cardiac Failure, 13, 476-481. doi:10.1016/j.cardfail.2007.03.010
[19] Levey, A.S., Bosch, J.P., Lewis, J.B., Greene, T., Rogers, N. and Roth, D. (1999) A more accurate method to estimate glomerular filtration rate from serum creatinine: A new prediction equation. Modification of diet in renal disease study group. Annals of Internal Medicine, 130, 461-470.

[20] Jessup, M., Abraham, W.T., Casey, D.E., Feldman, A.M., Francis, G.S., Ganiats, T.G., Konstam, M.A., Mancini, D.M., Rahko, P.S., Silver, M.A., et al. (2009) 2009 focused update: ACCF/AHA Guidelines for the diagnosis and management of heart failure in adults: A report of the American College of Cardiology Foundation/ American Heart Association Task Force on practice guidelines: Developed in collaboration with the International Society for Heart and Lung Transplantation. Circulation, 119, 1977-2016.

doi:10.1161/CIRCULATIONAHA.109.192064

[21] Dickstein, K., Cohen-Solal, A., Filippatos, G., McMurray, J.J., Ponikowski, P., Poole-Wilson, P.A., Stromberg, A., van Veldhuisen, D.J., Atar, D., Hoes, A.W., et al. (2008) ESC Guidelines for the diagnosis and treatment of acute and chronic heart failure 2008: The Task Force for the diagnosis and treatment of acute and chronic heart failure 2008 of the European Society of Cardiology. Developed in collaboration with the Heart Failure Association of the ESC (HFA) and endorsed by the European Society of Intensive Care Medicine (ESICM). European Heart Journal, 29, 2388-2442. doi:10.1093/eurheartj/ehn309

[22] Cleland, J.G., Cohen-Solal, A., Aguilar, J.C., Dietz, R., Eastaugh, J., Follath, F., Freemantle, N., Gavazzi, A., van Gilst, W.H., Hobbs, F.D., et al. (2002) Management of heart failure in primary care (the IMPROVEMENT of Heart Failure Programme): An international survey. Lancet, 360, 1631-1639. doi:10.1016/S0140-6736(02)11601-1

[23] Chioncel, O., Vinereanu, D., Datcu, M., Ionescu, D.D., Capalneanu, R., Brukner, I., Dorobantu, M., Ambrosy, A., Macarie, C. and Gheorghiade, M. (2011) The Romanian acute heart failure syndromes (RO-AHFS) registry. American Heart Journal, 162, 142-153.

[24] Heidenreich, P.A., Hernandez, A.F., Yancy, C.W., Liang, L., Peterson, E.D. and Fonarow, G.C. (2012) Get with the guidelines program participation, process of care, and outcome for medicare patients hospitalized with heart failure. Circulation Cardiovascular Quality and Outcome, $\mathbf{5}, 37-43$

[25] Fonarow, G.C., Abraham, W.T., Albert, N.M., Stough, W.G., Gheorghiade, M., Greenberg, B.H., O'Connor, C.M., Sun, J.L., Yancy, C.W. and Young, J.B. (2008) Influence of beta-blocker continuation or withdrawal on outcomes in patients hospitalized with heart failure: Findings from the OPTIMIZE-HF program. Journal of the American College of Cardiology, 52, 190-199. doi:10.1016/j.jacc.2008.03.048

[26] Nochioka, K., Shiba, N., Kohno, H., Miura, M. and Shimokawa, H. (2010) Both high and low body mass indexes are prognostic risks in Japanese patients with chronic heart failure: Implications from the CHART study. Journal of Cardiac Failure, 16, 880-887. doi:10.1016/j.cardfail.2010.06.413 
[27] Tsuchihashi-Makaya, M., Kinugawa, S., Yokoshiki, H., Hamaguchi, S., Yokota, T., Goto, D., Goto, K., Takeshita, A. and Tsutsui, H. (2010) Beta-blocker use at discharge in patients hospitalized for heart failure is associated with improved survival. Circulation Journal, 74, 1364-1371. doi:10.1253/circj.CJ-09-0993

[28] Bohm, M., Swedberg, K., Komajda, M., Borer, J.S., Ford, I., Dubost-Brama, A., Lerebours, G. and Tavazzi, L. (2010) Heart rate as a risk factor in chronic heart failure (SHIFT): The association between heart rate and outcomes in a randomised placebo-controlled trial. Lancet, 376, 886-894. doi:10.1016/S0140-6736(10)61259-7

[29] McAlister, F.A., Wiebe, N., Ezekowitz, J.A., Leung, A.A. and Armstrong, P.W. (2009) Meta-analysis: Beta-blocker dose, heart rate reduction, and death in patients with heart failure. Annals of Internal Medicine, 150, 784-794.

[30] Hori, M., Sasayama, S., Kitabatake, A., Toyooka, T., Handa, S., Yokoyama, M., Matsuzaki, M., Takeshita, A., Origasa, H., Matsui, K., et al. (2004) Low-dose carvedilol improves left ventricular function and reduces cardiovascular hospitalization in Japanese patients with chronic heart failure: The multicenter carvedilol heart failure dose assessment (MUCHA) trial. American Heart Journal, 147, 324-330. doi:10.1016/j.ahj.2003.07.023

[31] Bouvy, M.L., Heerdink, E.R., Leufkens, H.G., Hoes, A.W. (2003) Patterns of pharmacotherapy in patients hospitalised for congestive heart failure. European Journal of Heart Failure, 5, 195-200. doi:10.1016/S1388-9842(02)00256-8 